\title{
Outcome of immediate postpartum insertion of IUCD - A prospective study
}

\author{
Urmila Tripathi ${ }^{1}$, Durga $S_{a h u^{2}}{ }^{* *}$ \\ ${ }^{\mathbf{1}}$ Associate Professor, ${ }^{2}$ Resident Surgical Officer, Dept. of Obstetrics and Gynecology, Gajra Raja Medical College, Gwalior, \\ Madhya Pradesh, India \\ *Corresponding Author: Durga Sahu \\ Email: durgasahu16@gmail.com
}

Received: $4^{\text {th }}$ June, 2018

Accepted: $11^{\text {th }}$ August, 2018

\begin{abstract}
Introduction: Immediate postpartum intrauterine contraceptive device insertion is an excellent family planning method which provided safe effective, long term and reversible contraception to women in the delivery setting. Hence, the present study was undertaken to assess the clinical outcome of immediate postpartum insertion of intrauterine contraceptive device in terms of safety and efficacy and to compare the two routes of insertion i.e. in vaginal deliveries and cesarean section.

Objective: 1 . To study awareness level of PPIUCD among parturient. 2. To study safety and efficacy of PPIUCD insertion.

Materials and Methods: A cohort of 100 vaginal and 100 cesarean deliveries with PPIUCD insertion were studied over a period of 1 year and followed for three months in this prospective interventional study. Outcome measures of safety were perforation, irregular bleeding, unusual vaginal discharge and infection. Outcome measures of efficacy were pregnancy, expulsions, discontinuation and incidence of coiled up/ undescended strings. The data was compiled and analyzed.

Results: In the present study only $34.5 \%(\mathrm{~N}=69)$ of the study sample were aware of the PPIUCD while the rest $65.5 \%$ were unaware. No serious complications such as pregnancy or perforation were encountered in our series. Most common complication reported in both the groups was excessive bleeding PV followed by pain in lower abdomen. Spontaneous expulsion of the device was noted in $3 \%$ of vaginal insertions and none in the cesarean insertion.

Conclusion: PPIUCD is an excellent method to limit or space child births. It is offered to a woman in a setting when she is highly motivated and genuinely needs it.
\end{abstract}

Keywords: PPIUCD, Postpartum contraception, Insertion of IUCD.

\section{Introduction}

In developing countries, many unplanned and undesired pregnancies results from non use of contraception, most of which account to induced abortions. In a recent study of postpartum unintended pregnancies $86 \%$ resulted from non use of contraception. ${ }^{1}$ Continuation of these pregnancies is also associated with greater maternal complications and adverse perinatal outcomes. In India, $65 \%$ of women in the postpartum period have an unmet need of family planning. 2

Immediate postpartum insertion of intrauterine contraceptive devices (I-PPIUCD) is a safe, private and highly convenient choice for women who desire long acting reversible, effective, coitus-independent, non hormonal protection from pregnancy. It does not interfere with breast feeding and has few side effects, starting during the critical postpartum period, when the women is highly motivated for accepting a long term, reliable, feasible, safe and reversible contraception. At this time, the woman is already hospitalized with the health care provider for the child birth and leaves the hospital with an effective contraceptive in place.

I-PPIUCD insertion is an excellent opportunity to offer postpartum contraception to rural women having minimal access to medical care and infrequent and unreliable postpartum visit because of socioeconomic reasons.
Birth to pregnancy (BTP) interval of less than 24 months is associated with increased risk of maternal mortality, induced abortion and miscarriage. ${ }^{3}$ It is also associated with increased risk of preterm birth, small for dates, low birth weight babies and increased neonatal/infant mortality. ${ }^{4}$ Therefore, the recommended interval before attempting the next pregnancy is at least 24 months in order to reduce the risk of adverse maternal, perinatal and infant outcomes. ${ }^{5}$

Hence, this prospective interventional study was committed to find out the safety and efficacy of IPPIUCD insertion through the two routes i.e. vaginal deliveries and cesarean section. The outcome measures of safety were perforation, irregular bleeding, unusual vaginal discharge and infection. The outcome measures of efficacy were pregnancy, expulsion/ discontinuation of IUCD and coiled/ undescended IUCD strings.

\section{Objective}

1. To study awareness level of PPIUCD among parturient

2. To study safety and efficacy of PPIUCD insertion

\section{Materials and Methods}

This prospective interventional study was conducted in the Department of Obstetrics and Gynaecology of our institution after obtaining approval from institutional ethical committee. Two hundred 
postpartum subjects after contraception counseling constituted material for this study.

All eligible antenatal subjects hospitalized for delivery were given a cafeteria choice and counseled for I-PPIUCD. Consent was obtained from those who opted for insertion of I-PPIUCD, they received $\mathrm{CuT}$ 380A.

The study subjects were divided into two groups:

Group A: Post placental insertion following vaginal deliveries (100 cases).

Group B: Post placental insertion, intra cesarean (100 cases).

The acceptance rate of PPIUCD and the continuation rates were recorded, the reasons for acceptance was also recorded.

Post placental insertion was done by

1. Manual technique

2. Long ring forceps technique (Inserter recommended by WHO is Kelly's placental forceps)

\section{Insertion following Vaginal Delivery}

Manual Technique: This technique is used only within 10 minutes following the delivery of placenta. In this period the cervix is still almost fully dilated. This allows the passage of either forceps or the hand. After the active management of 3rd stage of labour is complete bimanual examination was performed to ensure empty uterine cavity. Implementing active management of third stage of labour (AMTSL) is the first step for a safe IUCD insertion.

The uterus was palpated to evaluate the height of the fundus and its tone. Aseptic techniques were followed, perineum was cleaned with povidone-iodine and vaginal walls inspected for lacerations. Sims speculum was inserted gently and cervix clean and visualized. IUCD pack was aseptically opened and CuT was held in right hand and slowly inserted through the cervix into the lower uterine cavity. Left hand was placed on abdomen on top of a sterile towel over the fundus of the uterus. CuT was slowly moved upwards until fundus of uterus can be felt.

The hand over the fundus and $\mathrm{CuT}$ are approximated and then IUCD was left at the fundus and the hand was slowly moved along the lateral wall of the uterus taking care not to dislodge the IUCD, while stabilizing the uterus with the outside hand. Strings were cut at the level of the cervix and Sims speculum removed. The woman continued in the lying down position for a few minutes to avoid a vasovagal collapse. The IUCD should be inserted prior to starting the repair of the multiple laceration of the vagina or episiotomy.

Long Ring forceps Technique: Post placental insertion of IUCD by ring/Kelly's forceps after vaginal delivery is much less painful to the client. It is easier to perform in the event that the client has a well contracted uterus and has benefited from AMTSL. With forceps insertion it is easier to the clinician to maintain appropriate infection prevention. Therefore, long sterile gloves or regular length gloves with a water impermeable apron are not required. During manual insertion the IUCD may be accidental displaced into the lower uterine cavity or pulled out actively when the hand is withdrawn. This problem is less likely with forceps insertion because forceps are slimmer than a hand.

Trans Cesarean Insertion: Following a cesarean delivery after the uterine angles are secured massage the uterus until the bleeding subsides. Make sure that uterine cavity is empty and haemostatic. Place the IUCD at the uterine fundus manually holding it between the index and middle finger or with a grasping instrument. Before stitching the uterine incision place the strings in the lower uterine segment near the internal cervical os. Do not pass the strings through the cervix because it increases the risk of infection.

Prior to discharge post insertion counseling and advice was given to each woman. Discharge Card showing type of IUCD and date of insertion were given. She was briefed about side effects of IUCD and normal postpartum symptoms. Woman was told when to return for IUCD follow-up/PNC/newborn checkup (6 weeks). She was notified to return anytime, if she observes foul smelling discharge different from the usual lochia, lower abdominal pain especially if accompanied by not feeling well, fever and chills, feeling of being pregnant or suspicion that IUCD has fallen out.

All the participants were called for follow up at 6 weeks and at 12 weeks interval. Various sociodemographic factors and outcomes were compared in the vaginal delivery and caesarean section groups. The comparison of complications like IUCD expulsion, bleeding, pain, infection and medical removal were studied. All the data were compiled and analyzed. Statistical analysis was carried out using SPSS 22.0.

\section{Observations}

The mean age of study subjects was $27.5 \pm 3.1$ years (Range 24-35 years).

A sizable number 106 (53\%) of primiparous woman accepted I-PPIUCD. There was nearly equal distribution of primiparous and multiparous women who accepted I-PPIUCD. There was no significant difference in the percentage of the two groups.

Majority of the women $(42.5 \%)$ had their last child birth less than 2 years ago in this study. 
Table 1: Distribution of cases according to educational status and awareness.

\begin{tabular}{|l|c|c|c|}
\hline \multirow{2}{*}{ Educational Status } & \multirow{2}{*}{ No. (\%) } & \multicolumn{2}{|c|}{ Awareness } \\
\cline { 3 - 4 } & & Aware & Unaware \\
\hline No Formal Education & $79(39.5)$ & 11 & 68 \\
\hline Primary & $89(44.5)$ & 30 & 59 \\
\hline Higher Secondary & $22(11)$ & 18 & 04 \\
\hline Graduates and above & $10(5)$ & 10 & 00 \\
\hline Total & 200 & $69(34.5 \%)$ & $131(65.5 \%)$ \\
\hline
\end{tabular}

A linear correlation was observed between the educated and uneducated women regarding awareness of I-PPIUCD. All graduate women were aware about PPIUCD.

Table 2: Side effects and complications

\begin{tabular}{|c|c|c|c|c|c|}
\hline \multirow{3}{*}{\multicolumn{2}{|c|}{ Side effects/Complications }} & \multicolumn{4}{|c|}{ Follow up schedule } \\
\hline & & \multicolumn{2}{|c|}{ 4-6 weeks } & \multicolumn{2}{|c|}{ 8-12 weeks } \\
\hline & & $\begin{array}{c}\text { Vaginal } \\
\text { deliveries }\end{array}$ & $\begin{array}{c}\text { Caesarean } \\
\text { sections }\end{array}$ & $\begin{array}{c}\text { Vaginal } \\
\text { deliveries }\end{array}$ & $\begin{array}{c}\text { Caesarean } \\
\text { sections }\end{array}$ \\
\hline \multicolumn{2}{|c|}{ Pain in Lower Abdomen } & 08 & 10 & 01 & 03 \\
\hline \multicolumn{2}{|c|}{ Excessive/prolonged bleeding PV } & 23 & 11 & 03 & 01 \\
\hline \multicolumn{2}{|c|}{ Unusual discharge per vaginum } & 10 & 03 & 04 & 01 \\
\hline \multicolumn{2}{|c|}{ Spontaneous Expulsion } & 02 & 00 & 01 & 00 \\
\hline \multirow{2}{*}{$\begin{array}{l}\text { Loss } \\
\text { Strings } \\
\end{array}$} & Misplaced IUCD & 02 & 01 & 03 & 02 \\
\hline & Coiled up thread & 02 & 01 & 00 & 03 \\
\hline \multicolumn{2}{|c|}{ Perforation } & 00 & 00 & 00 & 00 \\
\hline \multicolumn{2}{|c|}{ Pregnancy } & 00 & 00 & 00 & 00 \\
\hline
\end{tabular}

At the first follow up between 4-6 weeks, most common complication reported in both the groups was excessive bleeding PV followed by pain in lower abdomen. Spontaneous expulsion was reported more in vaginal deliveries $(n=2)$ then cesarean sections $(n=0)$. No case of perforation or pregnancy was reported during the study.

At the second follow up between 8-12 weeks, the vaginal delivery cases reported more complaints of excessive bleeding PV and unusual vaginal discharge. (Table 2)

Table 3: Indications for removal of IUCD in the two groups

\begin{tabular}{|l|c|c|}
\hline \multicolumn{1}{|c|}{ Indications } & $\begin{array}{c}\text { Vaginal } \\
\text { deliveries }\end{array}$ & $\begin{array}{c}\text { Caesarean } \\
\text { sections }\end{array}$ \\
\hline Pain in Lower Abdomen & 03 & 08 \\
\hline Menorrhagia & 08 & 04 \\
\hline Discharge Per Vaginum & 07 & 01 \\
\hline Misplaced IUCD & 05 & 03 \\
\hline Coiled up thread & 01 & 04 \\
\hline Total & 24 & 20 \\
\hline
\end{tabular}

In vaginal deliveries, the frequent reasons for IPPIUCD removal were menorrhagia and discharge PV which could not be relieved by the conservative treatment. In cases of cesarean sections the indications of removal were pain in abdomen, menorrhagia and coiled up thread. The overall discontinuation rate was $27 \%$ in vaginal deliveries and $20 \%$ in cesarean section (Table 3).
Table 4: Follow up details of I-PPIUCD acceptance

\begin{tabular}{|l|c|c|c|}
\hline $\begin{array}{c}\text { Subjects returning } \\
\text { for follow up }\end{array}$ & $\begin{array}{c}\text { Vaginal } \\
\text { deliveries }\end{array}$ & $\begin{array}{c}\text { Caesarean } \\
\text { Sections }\end{array}$ & Total \\
\hline 1st visit & 46 & 26 & 72 \\
\hline 2nd visit & 12 & 10 & 22 \\
\hline
\end{tabular}

Follow up percentage was not satisfactory. Only $36 \%$ came for the first follow up visit and $11 \%$ for the 2nd visit. Rests of the subjects were lost to follow up. (Table 4)

\section{Discussion}

CuT 380A endows with contraceptive protection equivalent to that achieved with tubal sterilization. ${ }^{6,7}$ The acceptance rates in different studies varied from $9.4 \%$ to $48.3 \%$ depending on their education status. ${ }^{8-13}$ One of the common reasons for non-use of contraception included lack of awareness as published in a report released by WHO in 2010 on unmet need for family planning. In the present study only $34.5 \%$ $(\mathrm{N}=69)$ of the study sample were aware of the PPIUCD while the rest $65.5 \%$ were unaware. Among those who were aware, maximum acceptance was seen in cases with secondary (81.81\%) and higher education (100\%). The awareness levels varied in different studies from $5.79 \%$ to $53.5 \%{ }^{8,11,14}$ In the present study $47.5 \%$ of the women were para- $1,37.5 \%$ were para- 2 and $14 \%$ were para-3. In other studies women with one child accepting IUCDs varied from $46.5 \%-73.17 \%$, women accepting IUCD having two or more children varied from $35.76 \%-47 \% . .^{15-17,10,14,18}$ 
More than a third of the parturient $(42.5 \%)$ who had the PPIUCD inserted had their last childbirth less than two years ago. In a report released by WHO in 2006, healthy timing and spacing of pregnancies has a direct effect on maternal health and newborn outcomes. In countries with high birth rates, about $32 \%$ of all maternal deaths and over one million deaths of children below 5 yrs could be prevented by healthy timing and spacing of pregnancies. This finding indicates a positive maternal health outcome in well spaced pregnancies, irrespective of the contraceptive used.

The duration since last child birth was significantly correlated with acceptance of PPIUCD in difference studies. ${ }^{9,10}$

Our study showed an expulsion rate of $10 \%$ in caesarean sections and $13.5 \%$ in vaginal deliveries. A cohort study also found significantly lower expulsion rates at the time of caesarean delivery compared to vaginal delivery. The expulsion rates in vaginal deliveries in other studies varied from $1.6 \%-10.7 \%$ by 6 months. ${ }^{19,16,14,20-22}$

We observed that the spontaneous expulsion is more common in vaginal deliveries $(\mathrm{N}=3)$ as compared to caesarean sections $(\mathrm{N}=0)$ that too more in immediate period following delivery.

It is noteworthy that there were no serious complications in this study. $23.5 \%(\mathrm{~N}=47)$ cases had menorrhagia, of these IUCD had to be removed in 12 cases as they did not respond to treatment given. Incidence of menorrhagia varied from $11.5 \%-27.23 \%$ in various studies. ${ }^{10,23}$ In the present study pain abdomen was reported in $10.5 \%$ cases $(\mathrm{N}=21)$ in this study. Pain was reported more in cases of caesarean sections $(\mathrm{N}=14)$ compared to vaginal deliveries $(\mathrm{N}=9) .11$ cases opted for PPIUCD removal out of 21 cases for this reason. Similar resulted were reported in other studies. ${ }^{24}$ There were no cases of perforation or pregnancy in the present study. This is in accordance with the other studies. ${ }^{25,26}$ In the present study, there were no cases of PID. About $10.5 \%$ of women in the present study reported pain in lower abdomen and 9\% reported with discharge per vaginum. The incidence of PID in women using IUDs is the same as in those who do not. ${ }^{27,28}$ Five women $(2.5 \%)$ among those inserted with PPIUCD had lost strings at four weeks and eight women (4\%) at 12 weeks. An ultrasound confirmed that the IUCD was in situ which indicated possible retraction or curling of the strings into the endocervical canal or uterine cavity. Despite reassurance, all of them got IUCD removed. In the end, continuation of PPIUCD was observed in $153(76.5 \%)$ cases. Absence of uterine perforation and low incidence of infection are strong indicators of safety. Immediate post-partum IUD insertion is common in a number of countries. ${ }^{29,30}$

\section{Conclusion}

We thus conclude from this study that postplacental IUCD is an effective method of contraception.
The expulsion rate of $10-15 \%$ also means that the retention rate is more than $85-90 \%$. In our country where access to care is limited and postpartum care is often infrequent, this level of programmatic achievement can be considered as high success.

In spite of very poor awareness among these women, the acceptance was high. It demands for developing strategies to increase public awareness of the PPIUCD through different media sources. The PPIUCD was demonstrably safe, having no reported incidence of perforation with low rates of expulsion, infection and lost strings. It is also important to impart training on PPIUCD in order to increase knowledge and skills among health care providers. This will aid in promoting PPIUCD use besides reducing expulsion rates. In a nation which moves with discounts, subsidies and incentives; cash incentives to the acceptor and motivation to the provider would bring a substantial increase in the usage of PPIUCD use in developing countries like India.

\section{References}

1. Yuang YM, Merkatz JZR, Kang ZJ. Postpartum unintended pregnancy and contraception practice among rural-to-urban migrant women in Shanghai. Contraception. 2012;86(6):731-738.

2. Postpartum IUCD Reference Manual, Family Planning Divsion. Ministry of Health and Family Welfare, Government of India, New Delhi, India 2010.

3. Agudelo AC, Belizan JM. Maternal morbidity and mortality associated with interpregnancy interval: cross sectional study. Br Med J. 2000;321(7271):1255-9.

4. Agudelo AC. Birth Spacing and the Risk of Adverse Perinatal Outcomes: A Meta-Analysis. JAMA 29. 2006:1809-1923.

5. World Health Organization. (2006). Birth spacing: report from a WHO technical consultation. Geneva: World Health

Organization http://www.who.int/iris/handle/10665/7371 0 .

6. United Nations Development Programme/UN Population Fund/WHO/World Bank, Special Programme of Research, Development and Research Training in human Reproduction. Long-term reversible contraception. Twelve years of experience with the TCu380A and TCu220C. Contraception. 1997;56:341-52.

7. Peterson HB, Xia Z, Hughes JM, Wilcox LS, Tylor LR, Trussell J. The risk of pregnancy after tubal sterilization: findings from the U.S. Collaborative Review of Sterilization. Am J Obstet Gynecol. 1996;174:1161-8.

8. Awadalla HI. Contraception Use among Egyptian Women: Results from Egypt Demographic and Health Survey in 2005. J Reprod Infertil. 2012;13(3):167-173.

9. Ali RAM. Acceptabilitya Safety of Postpartum Intrauterine Contraceptive Device among Parturients Muhimbili. National Hospital, Tanzania Muhimbili University of Health and Allied Sciences. November 2012.

10. Maluchuru S,V. Aruna, N. Prabhavathi, Postpartum Intrauterine Device Insertion - 2yr Experience at a Tertiary Care Center in Guntur Medical College /Govt. General Hospital, Guntur. IOSR. 2015;14(3):56-61. 
11. Katheit G, Agarwal J. Evaluation of post-placental intrauterine device (PPIUCD) in terms of awareness, acceptance, and expulsion in a tertiary care centre. Int $J$ Reprod Contracept Obstet Gynecol. 2013;2(4):539-543.

12. Choudhary, R.H. The influence of female education, labour force participation \& age at marriage on Fertility Behaviour in Bangladesh Social Biology. 1984;31(12):59-74.

13. Ullah, M.S. \& chakraborty, N. The use of modern \& traditional methods of fertility control in Bangladesh: a multivariate analysis. Contraception. 1994;50(4):363372.

14. Kumar S, Sethi R, Balasubramaniam S. Women's experience with postpartum intrauterine contraceptive device use in India. Reprod Health. 2014;11:32

15. Khan ME, Patel BC. Male involvement in family planning: a knowledge, attitude, behaviour and practice survey of Agra district. New Delhi: population council, 1997.

16. Bhalerao AR, Purandare MC. Post-puerperal Cu-T insertion: a prospective study. J Postgrad Med. 1989;35:70.

17. Kittur S, Kabadi YM. Enhancing contraceptive usage by post-placental intrauterine contraceptive devices (PPIUCD) insertion with evaluation of safety, efficacy, and expulsion. Int J Reprod Contracept Obstet Gynecol. 2012;1:26-32.

18. Grimes L. Immediate postpartum insertion of an IUD is safe \& effective. Global health technical briefs. Family Health International; 2007.

19. Tatum PR. Clinical aspects of intrauterine contraception. In: Anoniem. Infertiliteits informatorium Fertile Steril. 1977;28:3-28.

20. Treiman K, Liskin L, Kols A, Rinehart W. IUDs - an update. Popul Rep B. 1995;(6):1-35.

21. Thiery M. Pioneers of the intrauterine device. European Journal of Contraception and Reproductive Health Care. 1997;2(1):15-23.

22. Thiery M. Intrauterine contraception: from silver ring to intrauterine contraceptive implant. Eur J Obstet. Gynecol Reprod Biol. 2000;90(2):145-52.
23. Shukla M. Post-placental intrauterine device insertion - A five year experience at a tertiary care centre in north India. Indian J Med Res. 2012;136(3):432-435.

24. Stefan Welkovic, L Costa, A Faundes, R Ximenes, C Costa. Postpartum bleeding \& infection after postplacental IUD insertion. Contraception. 2001;63:1558.

25. El-shafei MM, Mashali A, Hassan EO, El Boghdadi L, El Lakkany N. Post partum and post abortion intra uterine device insertion unmet needs of safe reproductive health: 3 years experience of a Mansoura university hospital. Egypt Soc Obstet Gynaecol. 2000;26:253-62.

26. Ricalde Roger Lara, Gerardo Menacol Tobias, Carlos Ramos Parez, Norma Velazquez Ramirez.

Estudiocomparativo al azar entre los dispositiveos intrauterinos Multiload Cu375 y TCu 380A colocados durante ei postparto. Ginecol Obstet Mex. 2006;74:30611.

27. Kessel E. Pelvic Inflammatory Disease with Intra Uterine Devices use: a reassessment. Fertil Steril 1989, 51:6-10. Chi I. What we have learned from recent IUD studies: a researcher's perspective. Contraception. 1993;48:81-108.

28. Farley TMM, Rosenberg MJ, Rowe PJ, Chen JH, Meirik O. Intra- uterine devices and pelvic inflammatory disease: an international perspective. Lancet. 1992;339:7858.

29. Moran C, Fuentes G, Amado F, Higareda H, Bailon R, Zarate A. Postpartum contraceptive practice in hospitals of the federal District. Salud Publica de. Mexico. 1992;34:18-24.

30. Morrison C, Waszak C, Katz K, Diabate F, Mate EM. Clinical outcomes of two early postpartum IUD insertion programs in Africa. Contraception. 1996;53:17-21.

How to cite this article: Tripathi U, Sahu D. Outcome of immediate postpartum insertion of IUCD - A prospective study. Indian J Obstet Gynecol Res. 2018;5(4):511-515. 